\title{
High-dose steroids for the treatment of severe COVID-19 pneumonia: the need of the hour?
}

\section{To the Editor}

Ever since the results of the RECOVERY trial [1] were made public, steroids became the mainstay of the treatment of patients with moderate to severe COVID-19 pneumonia needing oxygen support. As the pandemic progressed and patients with moderate to severe disease requiring oxygen were treated with $6 \mathrm{mg}$ dexamethasone for 10 days, it soon came to light that the recommended dose did not show a significant mortality benefit. In clinical practice, high-dose steroids are used in disease processes involving high inflammatory activity such as auto-immune diseases, septic shock unresponsive to fluid resuscitation and vasopressors, chronic obstructive pulmonary disease (COPD) exacerbation, severe asthma, and allergy. Therefore, to consider high-dose steroids for the management of severe COVID-19 pneumonia is not a novel concept.

Edara et al. [2] published a case series where they treated two patients who were deteriorating on conventional regimen of steroid therapy with high doses of methylprednisolone reaching up to $500-750 \mathrm{mg} /$ day and reported a positive outcome. So et al. [3] treated seven patients with COVID-19 intubated secondary to acute respiratory distress syndrome with high-dose methylprednisolone 500-1000 mg/day and reported a positive recovery in all seven patients. A study from Iran [4] randomised sixty-eight hospitalised patients with confirmed severe COVID-19 into two groups with a ratio of $1: 1$, with one group receiving standard care with the addition of methylprednisolone pulse (intravenous injection,
$250 \mathrm{mg} /$ day $^{-1}$ for 3 days) and the second group receiving standard care alone (which included the conventional dose of the steroid). The number of patients with a clinical improvement was higher in the group receiving methylprednisolone pulse therapy as compared to the group receiving standard care ( $94.1 \%$ vs $57.1 \%$ ), and the mortality rate was lower in the methylprednisolone group (5.9\% vs $42.9 \%$; $p<0.001$ ). These studies, though not adequately powered, do raise a possibility of benefit to patients with severe disease when treated with high doses of steroid.

A question now arises on defining the subset of patients who would qualify for the high-dose steroid therapy. This query was answered by a recent study published by Spanish authors [5] to test whether high-dose corticosteroid pulse therapy $(1.5 \mathrm{mg} / \mathrm{kg} / 24 \mathrm{~h}$ of methylprednisolone or dexamethasone equivalent) was associated with increased survival in Covid-19 patients at risk of hyper-inflammatory response. The group provided with the initial criteria using laboratory markers to stratify these patients. The parameters proposed were (IL-6 $\geq 40 \mathrm{pg} / \mathrm{mL}$, and/or two of the following: C-reactive protein $\geq 100 \mathrm{mg} / \mathrm{L}$, D-dimer $\geq 1000 \mathrm{ng} / \mathrm{mL}$, ferritin $\geq 500 \mathrm{ng} / \mathrm{mL}$ and lactate dehydrogenase $\geq 300 \mathrm{U} / \mathrm{L}$ ) and a positive outcome was noted in the subjects receiving the higher doses.

These are times where the scientific knowledge is being updated on a daily basis and guidelines are changing every day in the light of new evidence. Under such circumstances the sound data available showing a benefit of high-dose steroids in severe COVID-19 pneumonia and the

Address for correspondence: Abhishek Tandon, Department of Pulmonary, Critical Care and Sleep Medicine. All India Institute of Medical Sciences, Jodhpur, India;

e-mail: drabhishektandon07@gmail.com

DOI: 10.5603/ARM.a2021.0084 | Received: 05.05.2021 | Copyright (C) 2021 PTChP | ISSN 2451-4934 | e-ISSN 2543-6031

This article is available in open access under Creative Common Attribution-Non-Commercial-No Derivatives 4.0 International (CC BY-NC-ND 4.0) license, allowing to download articles and share them with others as long as they credit the authors and the publisher, but without permission to change them in any way or use them commercially. 
criteria where they should be instituted warrants further investigation in the form of adequately powered randomised control trials to answer this new but pressing question - is this the need of the hour?

\section{Conflict of interest}

None declared.

\section{References:}

1. Horby P, Lim WS, Emberson JR, et al. RECOVERY Collaborative Group. Dexamethasone in hospitalized patients with Covid-19. N Engl J Med. 2021; 384(8): 693-704, doi: 10.1056/ NEJMoa2021436, indexed in Pubmed: 32678530.
2. Edara L, Suvvari TK, Kutikuppala LV. High dose steroid therapy to prevent severe hypoxia in COVID-19 patients: A potential solution for low resource clinical setting. Cureus. 2020; 12(12): e12330, doi: 10.7759/cureus.12330, indexed in Pubmed: 33520528.

3. So C, Ro S, Murakami M, et al. High-dose, short-term corticosteroids for ARDS caused by COVID-19: a case series. Respirol Case Rep. 2020; 8(6): e00596, doi: 10.1002/rcr2.596, indexed in Pubmed: 32514354.

4. Edalatifard M, Akhtari M, Salehi M, et al. Intravenous methylprednisolone pulse as a treatment for hospitalised severe COVID-19 patients: results from a randomised controlled clinical trial. Eur Respir J. 2020; 56(6), doi: 10.1183/13993003.02808-2020, indexed in Pubmed: 32943404 .

5. López Zúñiga MÁ, Moreno-Moral A, Ocaña-Granados A, et al. High-dose corticosteroid pulse therapy increases the survival rate in COVID-19 patients at risk of hyper-inflammatory response. PLoS One. 2021; 16(1): e0243964, doi: 10.1371/journal.pone.0243964, indexed in Pubmed: 33507958. 